\section{Health professionals' familiarity and attributions to mental illness}

\section{Aghukwa Nkereuwem Chikaodiri \\ Department of Psychiatry, Aminu Kano \\ Teaching Hospital, Kano, Nigeria}

\section{Abstract}

A few months from the time of this survey, the nearly completed inpatient psychiatric facility within the Aminu Kano Teaching Hospital's complex would be ready for admissions. Understanding the health workers' level of experience of mental illness and their likely behavioural responses towards people with psychiatric illness, therefore, should be a good baseline to understanding their likely reactions towards admitting such patients within a general hospital setting.

The study, which used a pre-tested and adapted attribution questionnaire, was prospective and cross-sectional. Randomly selected health workers in Aminu Kano Teaching Hospital had their level of familiarity and attributions towards psychiatric patients assessed.

The respondents showed a high level of experience with mental illness, with more than 3 in 5 of them having watched movies on mental illness before. More than half of them held positive (favorable) attributions towards persons with mental illness on nine of the ten assessed attribution factors. Almost all held negative (unfavourable) opinion towards intimate relationships with such persons. Attribution factors, "Responsibility, "Anger", "Dangerousness", "Fear" and "Segregation" were significantly related to the respondents' level of education $(\mathrm{P}<0.05)$. Marital status of the respondents related significantly to "Pity" and "Avoidance" factors $(\mathrm{P}<0.05)$. Having watched movies on mental illness significantly related to "Responsibility" and "Fear" factors $(\mathrm{P}<0.05)$.

Programs designed to improve the health workers mental health literacy, and increased positive professional contacts with mentally ill persons on treatment, would further enhance their perceived positive attributions towards them.

\section{Introduction}

Prejudice and stereotyping play strong roles in the cause of the additional social handicaps people with mental illness experience. ${ }^{1}$

The role health professionals attach to someone they perceive as mentally ill influences their preference for where such a person should receive treatment. In addition, their level of mental health literacy ("Knowledge and beliefs about mental disorders which aid their recognition, management or prevention"), ${ }^{2}$ and having had previous contacts with such persons were claimed to influence their attitude towards them. ${ }^{24}$

Some authors ${ }^{5,6}$ have claimed that attitude influences both professional and personal behaviour, especially stigma and discrimination towards someone with mental illness. However, mental health education and positive contact with persons with mental illness are capable of positively influencing knowledge about and attitudes towards mental illness. ${ }^{7-10}$

The present study assessed the health professionals' level of exposure to mentally ill persons, and their attributions towards someone with schizophrenia disorder, using a vignette depiction.

Attitudes vary with type of mental illness, and the mode of illness presentation in vignettes. ${ }^{11}$ Vignette presentation of a highly deviant character produces more negative responses from respondents than a character with less deviant descriptions ${ }^{11,12}$ However, being labeled mentally ill incurs stigmatizing attitudes from the public towards them. ${ }^{13}$

In order to elicit more sensitive measures of the respondents' attributions, a modified short and neutral statement about someone with schizophrenia was adapted from the "General Attribution Questionnaire-27", ${ }^{14}$ which has high reliability ${ }^{15}$ and factor structure. ${ }^{16}$

Relationships between the health workers' level of familiarity, their attributions to mental illness and some of their sociodemographic features were assessed.

This is the first study known to the author, surveying health professionals' familiarity to and their attributions towards psychiatric patients in the present area of study.

Differences between the health workers' attributions (if any) towards psychiatric patients and that of similar previous studies will be highlighted here.

The outcome of this study should serve as one of the guides to planning a general hospital based enlightenment programme on mental health issues.

\section{Materials and Methods}

\section{Design and setting}

This was a prospective and cross-sectional observational study, conducted at Aminu Kano Teaching Hospital, Kano, Nigeria.

A hospital had been established in 1988, and at that time, clinical services for the community were at a temporary site. In 1997, the hospi-
Correspondence: Aghukwa Nkereuwem

Chikaodiri, Department of Psychiatry,

Aminu Kano Teaching Hospital, Kano, Nigeria.

E-mail: drchikan@yahoo.co.uk

Key words: health professionals, attribution, mental illness.

Conflict of interest: the authors report no conflicts of interest.

Received for publication: 3 July 2009

Revision received: 9 December 2009

Accepted for publication: 21 December 2009

This work is licensed under a Creative Commons Attribution 3.0 License (by-nc 3.0)

(C)Copyright A.N. Chikaodiri, 2010

Licensee PAGEPress, Italy

Mental Illness 2010; 2:e1

doi:10.4081/mi.2010.e1

tal was relocated to its permanent site with beds for 500 inpatients (soon to be nearly $1,000)$ to cater for clients from Kano, other neighbouring states, and different parts of the country and beyond.

Psychiatric services are among the 17 clinical services available in the hospital. Currently, inpatient psychiatric care is offered in a temporary facility about 60 kilometers from the hospital complex.

Construction of the psychiatric wards on the permanent site commenced in February 2008, with the hope that they would soon be ready for inpatient psychiatric admissions.

\section{Instrument and method of data collection}

A pre-tested self-administered questionnaire was adapted for the study. The questionnaire was made up of three sections: section A had nine items that asked about some of the personal data of the respondents (e.g. age, sex, ethnic group, field of specialization etc.). Section B contained the 12-item "Level of Contact Report" ${ }^{17}$ This section contained lists of 12 ranked situations of varying degrees of intimacy that the respondent, might previously have had with persons suffering mental illness. This contained questions which ranged from the least intimate exposure such as, "I have never observed a person with mental illness" to medium intimacy contact, "I have worked with a person with mental illness" and high intimacy exposure as "I have a serious mental illness". A person, who had experienced mental illness, scored the maximum index of familiarity point of 12 while someone who had never observed a person with mental illness scored one. The index of familiarity was the rank score of the most intimate situation the respondent had experienced with mental illness. The last section contained a very short 
and neutral statement on "Bala" who works as a clerk in a law firm and has been hospitalized for schizophrenia, and modified questions that assessed the respondents' attributions towards him. The statement and questions were modified from the G-AQ 27 (General Attribution Questionnaire-27). ${ }^{14}$ Three items that were not in the original questionnaire were adapted into the present questionnaire to assess an attribute of "intimacy". Thus, the modified attribution questionnaire was comprised of 30 questions designed to examine 10 constructs (Responsibility, Pity, Anger, Dangerousness, Fear, Help, Coercion, Segregation, Avoidance and Intimacy) of the respondents' attributions towards Bala. A group of three question items represented one construct; for example, "I would feel annoyed having Bala as a neighbour", "How angry would you feel at Bala", and "How irritated would you feel by Bala" represented the construct "Anger". Responses were categorized into "Favourable" (scores 6-9), "Undecided" (score 5) and "Unfavourable" (scores 1-4) on a 9-point Likert scale for ease of analysis. Where applicable, there were score reversals with some of the responses.

The adapted questionnaire was pre-tested among 10 nurses, 10 doctors, and 5 medical records officers to determine their ability to understand the questions. In addition, the participants explained in a few words what the questions wanted to know from them, and necessary revisions were made from their comments.

\section{Sample size and sampling technique}

A minimum sample size of 248 at $95 \%$ confidence level and 5\% margin of error was computed $^{18}$ from the study population of 699 health professionals. This was comprised of 249 doctors, 380 nurses, 22 laboratory scientists, 14 social workers, 25 pharmacists, 25 medical records officers and 9 physiotherapists. ${ }^{19}$ An added $10 \%$ (to allow for possible attritions) of the deduced sample size to the figure gave a value of 273 as the required number of respondents for the survey. The method of sampling for the study was the stratified sampling technique with proportionate allocation of samples by fields of profession. The proportionate samples from the different professions were 97 doctors, 148 nurses, 9 laboratory scientists, 6 social workers, 10 pharmacists, 4 physiotherapists and 10 medical records officers. The respondents who picked the correct balloted numbers from each stratum filled the questionnaire. The hospital's ethical committee approved the research, and there was verbal approval from each respondent before being given the questionnaire to fill in. The respondents, were informed of the anonymity of their responses, and were asked to drop the completed questionnaires into a provided sealed receiver.

\section{Data analysis}

Data analysis was carried out with SPSS version 10 statistical software. ${ }^{20}$ Simple frequency distribution tables and absolute percentages to the nearest tenth were used to summarize categorical values. Summary statistics (eg. means, standard deviation), were used to describe quantitative variables where appropriate. Measurement of responses was on a 9-point Likert scale. Scale points 1 to 4 were coded as "Favourable", 5 was coded as "Neutral", while points 6 to 9 were coded as "Unfavourable". Responses that portrayed positive attributes towards the psychiatric patient in the questionnaire vignette indicated holding a favourable attribute towards that person. Responses that portrayed negative attributes towards the same psychiatric patient implied having an unfavourable attribute towards the person. There were score reversals in some of the questions to suit the responses, being either favourable or unfavourable. Tests of association between the respondents' familiarity indices, some of their sociodemographic characteristics, and their attributions to mental illness were determined with the $\chi^{2}$ test. A $\mathrm{P}$ value of $<0.05$ was considered statistically significant.

\section{Results}

Two hundred and fifteen (86.7\%) of the deduced sample size of 248 health professionals responded to the questionnaire. One hundred and thirty six $(63.3 \%)$ were males and 79(36.2\%) females.

Table 1 shows the summary of the respondents' sociodemographic characteristics.

\section{Respondents' familiarity with mental illness}

Table 2 shows the summary of the extent of the respondents' experience of mental illness. Twenty-nine (13.5\%) of the respondents had never observed a mentally ill person while 169 (78.6\%) had observed a mentally ill person in passing. One hundred and thirty-six (63.3\%) had watched movies on mental illness, while $129(60.0 \%)$ had provided services to the mentally ill before.

The respondents' mean familiarity index score was $7.94 \pm 2.29$.

\section{Attributions of respondents \\ towards psychiatric patients}

One hundred and forty-one (65.6\%) respondents did not hold the opinion that a mentally ill person was to blame for his/her illness. One hundred and eighty-four (85.6\%) were in favour of showing pity to someone with psychiatric illness, while 203 (94.4\%) gave favourable attributes towards offering help to
Table 1. Sociodemographic characteristics of the respondents.

\begin{tabular}{|c|c|c|}
\hline Variables & N. & $\begin{array}{l}\% \\
\text { missing }\end{array}$ \\
\hline \multicolumn{3}{|l|}{ Age } \\
\hline $\begin{array}{l}20-29 \\
30-39 \\
40-49 \\
50+ \\
\text { Mean }\end{array}$ & $\begin{array}{c}61 \\
93 \\
42 \\
6 \\
34 \pm 6.69\end{array}$ & $\begin{array}{c}28.4 \\
43.3 \\
19.5 \\
2.8\end{array}$ \\
\hline \multicolumn{3}{|l|}{ Sex } \\
\hline $\begin{array}{l}\text { Male } \\
\text { Female }\end{array}$ & $\begin{array}{c}136 \\
79\end{array}$ & $\begin{array}{l}63.3 \\
36.7\end{array}$ \\
\hline \multicolumn{3}{|l|}{ Level of Education } \\
\hline $\begin{array}{l}\text { Post secondary } \\
\text { University } \\
\text { Postgraduate }\end{array}$ & $\begin{array}{l}109 \\
79 \\
27\end{array}$ & $\begin{array}{l}50.7 \\
36.7 \\
12.6\end{array}$ \\
\hline \multicolumn{3}{|l|}{ Profession } \\
\hline $\begin{array}{l}\text { Doctors } \\
\text { Nurses } \\
\text { Pharmacists } \\
\text { Lab. Staffs } \\
\text { Physiotherapists } \\
\text { Med. Records }\end{array}$ & $\begin{array}{c}85 \\
100 \\
10 \\
6 \\
4 \\
10\end{array}$ & $\begin{array}{c}39.5 \\
46.5 \\
4.7 \\
2.8 \\
1.9 \\
4.7\end{array}$ \\
\hline \multicolumn{3}{|l|}{ Marital status } \\
\hline $\begin{array}{l}\text { Married } \\
\text { Not married } \\
\text { Divorced } \\
\text { Widowed }\end{array}$ & $\begin{array}{c}150 \\
60 \\
2 \\
3\end{array}$ & $\begin{array}{c}69.8 \\
27.9 \\
0.9 \\
1.4\end{array}$ \\
\hline \multicolumn{3}{|l|}{ Number of children } \\
\hline $\begin{array}{l}\text { None } \\
1-3 \\
4-6 \\
7+ \\
\text { Mean }\end{array}$ & $\begin{array}{c}73 \\
95 \\
38 \\
3 \\
1+1.89\end{array}$ & $\begin{array}{c}34.0 \\
44.2 \\
17.7 \\
1.7\end{array}$ \\
\hline \multicolumn{3}{|l|}{ Religion } \\
\hline $\begin{array}{l}\text { Islam } \\
\text { Christianity } \\
\text { Others }\end{array}$ & $\begin{array}{c}176 \\
39 \\
0\end{array}$ & $\begin{array}{c}81.9 \\
18.1 \\
0\end{array}$ \\
\hline Tribe & & 10.5 \\
\hline $\begin{array}{l}\text { Hausa } \\
\text { Ibo } \\
\text { Yoruba } \\
\text { Others }\end{array}$ & $\begin{array}{c}155 \\
11 \\
18 \\
30\end{array}$ & $\begin{array}{c}72.1 \\
5.1 \\
8.4 \\
14.0\end{array}$ \\
\hline
\end{tabular}

the same person. One hundred and eightyseven $(87.0 \%)$ of the health professionals did not favour feeling angered by someone with psychiatric illness, while 167 (77.7\%) of the same respondents were not in favour of feeling fearful of same person. One hundred and thirty-eight (64.2\%) of the respondents held favourable attributes about the dangerousness of the patient who was depicted in the vignette. In addition, 113 (52.6\%) were not in favour of avoiding the same person. However, $176(81.9 \%)$ of the respondents expressed unfavourable attributes towards having intimate social relationships with the supposed psychiatric patient in the vignette.

Table 3 shows a summary of the respon- 
Table 2. Respondents' extent of familiarity with psychiatric patients.

\begin{tabular}{|c|c|c|c|c|c|c|c|}
\hline N. & Variables & Yes & Percentage & No & Percentage & Missing & Percentage \\
\hline 1. & Never observed a mentally ill person & 29 & 13.5 & 186 & 86.5 & & \\
\hline 2. & Observed in passing a mentally ill person & 169 & 78.6 & 45 & 20.9 & 1 & 0.5 \\
\hline 3. & Watched movie on mental illness & 136 & 63.3 & 79 & 36.7 & & \\
\hline 4. & Watched television documentary on mental illness & 112 & 52.1 & 101 & 47.0 & 2 & 0.9 \\
\hline 5. & Frequent observation & 68 & 31.6 & 146 & 67.9 & 1 & 0.5 \\
\hline 6. & Worked with mentally ill person & 75 & 34.9 & 140 & 65.1 & & \\
\hline 7. & Job/services to mentally ill persons & 129 & 60.0 & 83 & 39.2 & 3 & 1.4 \\
\hline 8. & Provides services for mentally ill persons & 122 & 56.7 & 90 & 41.9 & 2 & 0.9 \\
\hline 9. & Family friend has mental illness & 71 & 33.0 & 143 & 66.5 & 1 & 0.5 \\
\hline 10. & Relative has mental illness & 49 & 22.8 & 165 & 76.7 & 1 & 0.5 \\
\hline 11. & Lives with someone with mental illness & 33 & 15.3 & 182 & 84.7 & & \\
\hline 12. & Has mental illness & 13 & 6.0 & 201 & 93.5 & 1 & 0.5 \\
\hline 13. & Mean familiarity index points & \multicolumn{6}{|c|}{$7.94 \pm 2.79$} \\
\hline
\end{tabular}

Table 3. Attributions of respondents towards persons with psychiatric illness.

\begin{tabular}{llrrrrrrrr}
\hline N. & Variables & Favorable & $\%$ & Neutral & $\%$ & Unfavorable & M & Missing \\
1. & Responsibility & 141 & 65.6 & 32 & 14.9 & 42 & 19.5 & \\
2. & Pity & 184 & 85.6 & 18 & 8.4 & 13 & 6.0 & \\
\hline 3. & Anger & 187 & 87.0 & 11 & 5.1 & 17 & 7.9 & \\
4. & Dangerousness & 138 & 64.2 & 20 & 9.3 & 57 & 26.5 & \\
\hline 5. & Fear & 167 & 77.7 & 16 & 7.4 & 32 & 14.9 & \\
6. & Help & 203 & 94.4 & 0 & 0.0 & 12 & 5.6 & \\
\hline 7. & Coercion & 155 & 72.1 & 14 & 6.5 & 45 & 20.9 & \\
\hline 8. & Segregation & 143 & 66.5 & 23 & 10.7 & 49 & 22.8 & \\
\hline 9. & Avoidance & 113 & 52.6 & 31 & 14.4 & 71 & 33.0 & \\
10. & Intimacy & 32 & 14.9 & 7 & 3.3 & 176 & 81.9 & \\
\hline
\end{tabular}

dents' attributions towards persons with psychiatric illness using an adapted 10-factor attribution questionnaire.

\section{Respondents' attributions towards psychiatric patients and some sociodemographic correlates}

Level of education and responsibility

Among the forty-two (19.5\%) respondents who felt a psychiatric patient was to blame for his or her illness, 30 (71.4\%) had post secondary educational qualifications, 11 (26.2\%) were university graduates, and one (2.4\%) had a postgraduate qualification $(\mathrm{P}=0.015, \mathrm{df} 4)$.

\section{Level of education and anger}

Seventeen (7.9\%) of the respondents would feel angry with a psychiatric patient. Sixteen (94.1\%) of them had post secondary certificates as their highest educational attainment, and one (5.9\%) was a university graduate. None of the respondents with a postgraduate certificate was in favour of the above attribute $(\mathrm{P}=0.003, \mathrm{df}=4)$.

\section{Level of education and dangerousness}

Fifty-seven (26.5\%) respondents responded negatively to the factors that attributed "dangerousness" to a psychiatric patient. Among these respondents, 43 (75.4\%) had postsecondary highest level of education, while 11 (19.3\%) were graduates. Three (5.3\%) of the respondents with the same attribute as above had postgraduate qualifications $(\mathrm{P}=0.001, \mathrm{df}=4)$.

\section{Level of education and fear}

Thirty-two (14.9\%) of the respondents would feel fearful towards a psychiatric patient. Within this number, 23 (71.9\%) had post-secondary qualification, and 9 (28.1\%) had university education. None of the respondents with postgraduate qualification would feel fearful towards a psychiatric patient $(\mathrm{P}=0.001, \mathrm{df}=4)$.

\section{Level of education and segregation}

Forty-nine (22.8\%) of the respondents were in support of segregating psychiatric patients, $38(77.6 \%)$ of them had post secondary level of education, 7 (14.3\%) were university graduates, and $4(8.2 \%)$ had postgraduate qualifications $(\mathrm{P}=0.001, \mathrm{df}=4)$.

\section{Marital status and pity}

Thirteen respondents responded negatively to pitying a psychiatric patient, of which 3 (13.1\%) were married and 10 (76.9\%) were not. The respondents' marital status was significantly associated with the feeling of pity towards a psychiatric patient $(\mathrm{P}=0.001, \mathrm{df}=8)$.

\section{Marital status and avoidance}

The number of respondents who would want to avoid someone with mental illness was 52 , of whom 42 (73.0\%) were married, 17 (24\%) not married, and 2 (3\%) were divorced. Marital status was significantly related to perceived avoidance of a psychiatric patient $(\mathrm{P}=0.022, \mathrm{df}=8)$.

\section{Correlations between the respon- dents' level of contact and attribu- tions to psychiatric patients}

Watched movies about mental illness and responsibility

One hundred and forty-one respondents (65.6\%) were in favour of not attributing responsibility of illness to a mentally ill person. Eighty-one (57.4\%) of these had watched movies on mental illness before and 60 (42.6\%) had not. Twenty (62.5\%) of the 32 respondents who maintained neutral responses had watched movies on mental illness. Among the 42 respondents who gave unfavourable responses to the above issue, 35 (83.3\%) had watched movies on mental illness before $(\mathrm{P}=0.009, \mathrm{df}=2)$.

Watched movies about mental illness and fear attribution

Among the 167 (77.7\%) respondents who 
would not be fearful of a psychiatric patient, $106(63.5 \%)$ had watched movies on psychiatric illness before. Twenty-four (75.0\%) of the 32 (14.9\%) respondents who gave negative responses to the fear factor had watched movies on mental illness before. Seventy-nine (36.7\%) of the respondents had not watched movies on mental illness before, among whom $22(36.5 \%)$ would be fearful of a psychiatric patient $(\mathrm{P}=0.039, \mathrm{df}=2)$.

\section{Discussion}

The results of the survey showed that the majority of the hospital workers had had contacts with psychiatric patients in the past. Many, who were undecided, or held the opinion that a mentally ill person was to blame for his/her illness, had watched movies on mental illness in the past. In addition, more of the respondents who watched similar movies in the past than those who did not, felt the depicted psychiatric patient in the vignette was dangerous. A challenging source of stigmatization of mental illness is from media depictions ${ }^{14,21}$ as is portrayed in a few Nigerian movies: Onyeka Onwuenu's "Conspiracy", Regina Askia's "High way to grave" and Pete Edochia's "Chain reaction". These movies present mental illness as a mark of punishment from the gods for wrong doings or as something inflicted by evildoers.

The majority of the health workers were positive about psychiatric patients on 9 of the 10 attribution factors. This finding was to be expected since the description of the patient in the vignette did not give the respondents a perception of dangerousness about him. Fear of a psychiatric patient has a specific relationship with perceiving the same person as dangerous, which in turn leads to avoidance behaviour and social distancing. ${ }^{14,22}$ However, similar to what has been found in previous studies, ${ }^{14}$ more than 4 in every 5 of the respondents would not want to associate with psychiatric patients in such intimate relationships as having them as in-laws. Labeling and grouping of people with mental illness by the public as people who are unpredictable, probably dangerous, and with an incurable illness is a misconception. ${ }^{23}$ The probable outcome of these opinions is an emotional "fear of the unknown", hence the tendency of the "normal" members in the society to shy away from them, especially in social and cultural situations that warrant intimacy, such as in marriage.

More than 3 in 5 of the health workers said that the described psychiatric patient was not to blame for his illness, about $86 \%$ would show pity and while more than $94 \%$ favoured helping that person. Weiner's attribution theory claimed that respondents would likely be angry with people viewed as responsible for their mental illness and would not be willing to help them. On the contrary, respondents are more likely to pity and be willing to help psychiatric patients who have been victimized for their mental illness. ${ }^{24}$

An individual's knowledge of and experience with mental illness has been shown to influence his/her perception of the dangerousness of a psychiatric patient. ${ }^{14}$ Despite a neutral presentation of the patient in the questionnaire, the respondents' high level of experiencing mental illness could have contributed to the observed favourable attributions towards him.

The respondents' level of education had a positive correlation to their attributions towards mentally ill persons especially in aspects of responsibility, anger, dangerousness, fear and segregation. Some studies ${ }^{3,9,10,25}$ in Nigeria claimed that the level of education positively related to the respondents' attitude to mental illness. As was found in this study, respondents with postgraduate qualifications held less negative attributions towards persons with mental illness than those with university degrees who in turn were less stigmatizing than those with post-secondary qualification.

Being married was associated with expressing more pity to a mentally ill person but was also significantly related to seeing such a person as dangerous, therefore, greater expression of attributions that indicated avoidance of such a person. The thought of having one's loved one suffer mental illness, probably influenced the more favourable expression of pity by the married respondents towards them. Likewise, naturally, the basic tendency to protect one's loved ones from harm or potentially viewed source of harm may not be unrelated to the earlier respondents' expression of more unfavourable responses that portray avoidance of persons with mental illness. However, there were no significant associations between sex, number of children or having a relation with mental illness by the respondents and their attitude towards the mentally ill.

\section{Limitations}

The study attempted to elicit the reasons behind certain behaviours (attribution) towards psychiatric patients, but sometimes opinions or beliefs (attitude) may not truly explain behaviours.

The vignette description was that of an apparently harmless psychiatric patient, which could have influenced the attributions of the respondents' towards him.

The study did not use expansive structured and standardized scales measuring specific attitudinal issues since assessment was on attributions.

Respondents, being health professionals, could have responded in ways generally expected of them, thereby not actually expressing their true attributes (positive response effect) towards psychiatric patients.

The repeat of the survey on more diverse and larger groups' of health professionals is vital to making a generalized opinion on their attributions towards mentally ill persons.

Despite this being an observational study, the author knows of no similar study having been conducted in the present field. In addition, the present study is a pilot to future interventional studies on similar issues.

\section{Conclusions}

The study showed that most of the health professionals were quite familiar with psychiatric patients, and that many expressed favourable attributions towards the depicted psychiatric patient in the vignette. However, familiarity through movies had significant negative attribution effects. Higher educational qualification related more favourably to some attribution factors such as "Responsibility" and "Dangerousness". Being married had both positive and negative attribution effects on the respondents towards "pity" and "dangerousness" of the mentally ill. Almost all respondents held negative opinions towards "Intimacy" with mentally ill persons.

\section{Recommendations}

There is a need to increase the health workers' level of positive contacts with mentally ill persons on treatment. This could be by rotational duties or postings that would include working in the psychiatric wards/clinics together with professionals trained in the care of mental and behavioural disorders.

The department of psychiatry should be part of the hospital's TRIAGE program and, by this, create beds for physically disordered patients. Probably, management of these patients for short periods of time by the responsible specialist unit/s in the psychiatric ward would strengthen the perceived favourable attributions of the professionals towards people with mental illness.

The hospital should encourage the department in organizing high impact seminars and other relational programmes on mental health issues, as a way of improving the Health professionals' and workers' "Mental Health Literacy".

There should be cohesive and efficient team work among the various units in the department to enable the staff to manage to the best of their ability emergency psychiatric problems concerning patients in their care, especially such patients who, if not properly cared for, could make many people wary and uncomfortable. 


\section{References}

1. Crisp AH, Gelder MG, Rix S, et al. Stigmatization of People with mental illnesses. Br J Psych 2000;177:4-7.

2. Jorm AP, Korten AE, Jacomb PA, et al. 'Mental Health Literacy': a survey of the public's ability to recognise mental disorders and their beliefs about the effectiveness of treatment. Med J Australia 1997; 166:182-86.

3. Ogunlesi A0, Adelekan ML. Nigerian Primary Health Care Workers: a pilot Survey on attitude to mental health. Bull Royal College Psychiatr 1988;441-2.

4. Tipper R, Mountain D, Lorimer S, McIntosh A. Support Workers attitudes to mental illness: implications for reducing stigma. Psych Bulletin 2006;30:179-81.

5. Joel D, Sathyaseelan M, Jayakaren R, et al. A biomedical educational intervention to change explanatory models of Psychosis among community health workers in South India. Indian J Psych 2006;48:13842.

6. Foster K, Usher K, Baker JA, et al. Mental health workers' attitudes toward mental illness in Fiji. Australian J Adv Nursing 2007;25:3.

7. Aghanwa, HS. Attitude toward and knowledge about mental illness in Fiji Islands.
Int J Social Psych 2004;50:361-75.

8. Gureje 0, Lasebikan V0,Oluwanuga OE, et al. Community Study of Knowledge of and attitude to mental illness in Nigeria. Br J Psych 2005;186:436-41.

9. Awaritefe A, Ebie JC. Complementary attitudes to mental illness in Nigeria. African J Psych 1977;1:37-43.

10. Odejide A0, Olatawura MO. A Survey of Community attitude to the Concept and treatment of mental illness in Ibadan. Nigerian Med J 1979;9:343-7.

11. Luty J, Fekadu 0, Umoh 0, Gallagher J. Validation of a short instrument to measure stigmatised attitudes towards mental illness. Psych Bulletin 2006;30:257-60.

12. Wolff G, Pathare S, Creig T, Leff J. Community Knowledge of mental illness and reaction to mentally ill people. $\mathrm{Br} \mathrm{J}$ Psych 1996;168:191-8.

13. Crisp AH, Gelder GM, Rix S et al. Stigmatization of people with mental illness. Br J Psych 2000;177:4-7.

14. Corrigan PW, Green A, Lundin R, et al. Familiarity with and Social distance from people who have serious mental illness. Psychiatric services 2001;52:953-8.

15. Corrigan PW, Markowitz FE, Watson A, et al. An attribution model of public discrimination towards persons with mental illness. J Health Social Behaviour 2003;44: 162-79.
16. Corrigan PW, Rowan D, Green A, et al. Challenging two mental illness stigmas: Personal responsibility and dangerousness. Schizophrenia Bulletin 2002;28: 293 309.

17. Holmes EP, Corrigan PW, Williams P, et al. Changing attitudes about schizophrenia. Schizophrenia Bulletin 1999;25:447-56.

18. The survey system. Sample size calculator. www.surveysystem.com/sscalc.htm

19. Pensions office - Aminu Kano Teaching Hospital Manual abstract 2007.

20. Norusis MJ SPSS/PC+V 10.0 Base Manual Chicago: SPSS Inc.

21. Wahl OF. Media Madness: Public images of mental illness. New Brunswick NJ Rutgers University Press; 1995.

22. Corrigan PW, Watson AC. Understanding the impact of stigma on people with mental illness. World Psychiatry 2002;1:16-20.

23. Wolff G, Pathare S, Craig T, et al. Community knowledge of mental illness and reaction to mentally ill people. Br J Psych 1996; 168,191-8.

24. Corrigan PW, Lurie BD, Goldman HH, et al. How adolescents perceive the stigma of mental illness on alcohol abuse. Psych Services 2005;56:544-50.

25. Binitie AO. Attitudes of educated Nigerians to psychiatric illness. Acta Psychiatrica Scand 1970;46:391-8. 